\title{
The prevalence of Infectious Bronchitis (IB) in some chicken farms in Egypt: I. Spotlight on the status of IB outbreaks in some chicken flocks
}

\author{
K. M. Kamel ${ }^{1}$, A. A. Bassiouni ${ }^{2}$, M. A. Afify ${ }^{2}$, N.S. Rabie ${ }^{2}$ \\ 1Department of Poultry Diseases, National Research Center, Cairo and ${ }^{2}$ Department of Poultry \\ Diseases, Faculty of Veterinary Medicine, Cairo University.
}

\begin{abstract}
Twenty five isolates of IBV were isolated from 36 broiler and layer chicken farms collected from 13 governorates during 2 years started from January 2003. Sixteen farms were vaccinated against IB, and 9 farms were not vaccinated. The cardinal signs of the disease in layers were drop in egg production, with watery albumen, inferior (pale and misshape shell) eggs, un-noticed respiratory distress and pectoral myopathy, and those in broilers were respiratory distress, renal urate deposition and death beyond 4 weeks of age (late mortality). The viruses were isolated and identified by chicken embryo, and CEK cell culture inoculation.
\end{abstract}

Infectious bronchitis virus (IBV) is the causative agent of the famous disease internationally known as infectious bronchitis (IB) that causes high economical losses in poultry. Infectious bronchitis is one of well known respiratory and urogenital disease of chickens (Cavanagh and Naqi, 1997), all over the world since 1931, but specifically in 1954 in Egypt (Ahmed, 1954). It is well known that the primary target tissue of IBV infection is the respiratory tract, though some strains also replicate in the kidneys and oviduct, causing nephritis and reduced egg production; respectively. IBV has a constant threat to the poultry industry because of the isolation -now and then - of new variant serotypes of the virus even from vaccinated flocks of different immune status (Gelb, 1989; Wang and Tsai, 1996). Till now, more than 60 serotypes or IBV variants have been identified worldwide (Ignajatovic and Sapats, 2000; Yu et al., 2001), against which little or even no-cross protection existed. Because of this fact, determining and updating the exact serotypic identity of field strains prevalent in poultry farms in Egypt is very essential for selecting the effective vaccine capable to overcome the problem of IB disease in Egypt.

For an effective vaccination program, the isolation and identification of IBV isolates are important because vaccines are selected on the basis of the serotypes present in specific geographic areas (Yu et al., 2001).
In Egypt, IB was first described by Ahmed (1954), subsequently several reports (Eissa et al., 1963; Ahmed, 1964; Amin and Moustageer, 1977; Sheble et al., 1986; Bastami et al., 1987; Mousa et al., 1988; El-Kady, 1989; Mahmoud, 1993; Ahmed, 2002; Abdel Moneim et al., 2002; Madbouly et al., 2002; Sultan et al., 2004; Lebdah et al., 2004; Sediek, 2005) emphasized the prevalence of the disease as reviewed in the present review. Massachusetts (Mass) type live attenuated vaccine (H120) as well as inactivated oil emulsion vaccine are applied to prevent and control the disease.

The aim of this study was to investigate the prevalent IBV in Egypt and their evolutionary relationship. The present work was carried out to know whether the recently isolated Egyptian IBV strains which escaped from vaccine- elicited immunity were newly introduced in the chicken population or arise by mutations of circulating Egyptian IBV strains .This is important for implementation of control measures especially for the future vaccination strategies.

\section{Materials and methods}

\section{Viruses of IB.}

Field isolates. Affected and freshly dead birds were collected from 36 chicken farms showing symptoms suspected to be IBV infection. The collected birds were killed, necropsied and examined for gross post mortem (PM) lesions. Specimens for IBV isolation included trachea, lung, kidney and cecal tonsils were collected under aseptic condition according to Jose et al., (2000). 
IB AGP antigen. It was supplied from, Charles River Laboratories, SPAFAS. Co., catalog No. 536216; in a lyophilized form and reconstituted by addition of $1.0 \mathrm{ml}$ sterile PBS buffer (according the direction of manufactures). Reconstituted antigen stored at $-20^{\circ} \mathrm{C}$ till used as positive control in AGPT of CAM homogenate of the inoculated SPF eggs.

Serum.

Serum Samples. Sera were separated and checked by Synbiotic ELISA test kits for detection of specific IBV antibodies.

Positive infectious bronchitis virus
precipitating antiserum. Antiserum was supplied from Holland, Diventure. IBV AGP/GDT antiserum, Lot No. 20102-140400, in a lyophilized form and reconstituted by addition of $1.0 \mathrm{ml}$ sterile PBS buffer (according the direction of manufactures). Reconstituted antiserum was stored at $-20^{\circ} \mathrm{C}$ till used in detection of IBV antigen in the CAM homogenate of the inoculated SPF eggs by AGPT.

Experimental hosts.

Fertile chicken egg. The fertile chicken eggs used through the present study were Specific Pathogen Free (SPF) eggs originated from Nile SPF (Koom Oshiem, Fayoum, Agriculture Research Center- Ministry of Agriculture). The fertile chicken eggs were used for isolation of IBV by egg inoculation, preparation of chicken embryo kidney cells (CEK) and titration of the isolated IBV isolates.

Cell culture. Monolayer cultures of primarily chicken embryo kidney cells (CEK) were prepared from the kidneys of 19-20 day old specific pathogen free (SPF) chicken embryo according to (Villegas and Purchase, 1990).

Solution for Scanning Electron Microscope (SEM). 5\% Glutaraldehyde was prepared as described by (Dutta, 1975).

Preparation of samples for IBV isolation (Jose et al., 2000). The collected organs (Trachea, lung, kidney, cecal tonsils) were washed in sterile $0.85 \%$ saline, and then frozen at below$10^{\circ} \mathrm{C}$. After thawing, the tissue homogenates $(10 \% \mathrm{~W} / \mathrm{V})$ were prepared in sterile saline $0.85 \%$ containing $1000 \mathrm{IU} / \mathrm{mL}$ penicillin, $1.0 \mathrm{mg} / \mathrm{ml}$ streptomycin. By disrupting organs using sterile mortar and pestle, the homogenates were then centrifuged at $3000 \mathrm{rpm}$ for $10 \mathrm{~min}$, and the supernatant was further passed through $45 \mu \mathrm{m}$ membrane filter. Sterility of the inocula was checked pre-inoculation by culturing on nutrient agar and sabouraud's glucose agar. These materials were examined for presence of IBV by passage in embryonated eggs.

Specific Pathogen Free (SPF) embryonated chicken egg inoculation (Gelb and Jackwood, 1998). Five to eight 9-11-day-old SPF embryonated chicken eggs were used for inoculation of each sample via the allantoic sac route. $0.2 \mathrm{~mL}$ of the inoculum was inoculated per egg. On day 3 post-inoculation (pi), survival embryos were killed and chorioallantoic fluid and chorioallantoic membrane (CAM) were harvested aseptically from inoculated eggs Chorioallantoic fluid was tested for sterility to be free from bacteria and fungi by culturing on nutrient agar and sabouraud dextrose agar, and tested for haemagglutination (HA) reaction with $10 \%$ chicken red blood cells (CRBCs) (to exclude haemagglutinating agents). The harvest fluids were inoculated for two passages $\left(2^{\text {nd }}\right.$ and $3^{\text {rd }}$ )(some of IBV field isolates were not embryo- adapted and did not cause death or produce lesions on the first passage (Gelb and Jackwood, 1998), so, further, 2 additional passages $\left(4^{\text {th }}\right.$ and $\left.5^{\text {th }}\right)$ were performed, each in 58 embryos and observed for typical IB lesions, such as dawarfing and stunting (judged by weight if the difference was of $25 \%$ or more between infected and normal embryos of the same age, may be considered evidence of IBV infection (Anon, 1963). Chorioallantoic membranes harvest homogenates were tested in AGP test (Woernle, 1966) for evidence of IBV infection.

Agar gel precipitation test (AGP). The test was used to demonstrate the presence of IBV antigen in the harvests of chorioallantoic membranes (CAMs). The test was performed according to Chubb and Cumming (1972). Reading were taken 24-48 hours after filling with an oblique light in a dark room.

\section{Isolation of IBV in chicken embryo kidney} (CEK) cells.

Chicken embryo kidney (CEK) cell culture preparation. These cultures were prepared from kidneys of 19 to 20-day-old SPF chicken embryos according to (Villegas and Purchase, 1990).

Inoculation of CEK cell culture by IBV isolates (Villegas and Purchase, 1990). $0.1 \mathrm{ml}$ of IBV (allantoic harvest) at the level of the $5^{\text {th }}$ embryonic passage for each isolates (positive in AGP test), were inoculated into separate tissue culture plate, the plates rocked gently for evently distribution of the inoculum over the cell monolayer. 
Inoculated cultures were incubated at $37^{\circ} \mathrm{C}$ for 45 minutes to allow virus adsorption. The plates were rocked once or twice during incubation. $2 \mathrm{ml}$ of MEM contain $5 \%$ calf serum was added to each plate. Plates were then incubated at $37^{\circ} \mathrm{C}$ with $0.5 \% \mathrm{CO}_{2}$ with daily observation for cytopathic effect (CPE). If no CPE for up to 48-72 hours, re-passage was performed. For re-passage, the samples were harvested after 3 cycles of freezing and thawing, then collected and used for a second serial passage.

\section{Results}

Characteristic of IB outbreaks in poultry farms. The present data represent prospective survey of the presence of IB disease in 36 chicken farms. The data collected from 13 governorates during 2 years started from January 2003 and involved different types of chickens, including broilers, layers and broiler breeders (Table 1).

In broiler farms (Table 2) out of 24 examined farms, 9 farms with history of previous vaccination against IB which represent $37.5 \%$, and 15 farms without history of vaccination, which represented $62.5 \%$. The main clinical signs were difficult breathing, tracheal rales, coughing, sneezing with or without nasal discharge, wet eye was observed and an occasional chick had swollen sinus (Fig. 1A). Elevated mortality was observed beyond 4 weeks and persisted for the end of fattening period with range of $5-25 \%$. A generalized weakness was observed, accompanied by depression. Feed consumption and body weight were markedly reduced. Soiled vent feather was recorded as accompanied by slight diarrhea or soft feces and wet litter (Fig. 1B). On necropsy, the trachea was congested with excessive amounts of mucous (Fig. 2). Casious exudate in trachea and its biforcation as a plug was seen. Air sacs showed variable observations including cloudy, turbid with or without yellow casious exudates. Most of examined chicks were associated with pericarditis, perihepatitis and enteritis. Sometimes small area of pneumonia was observed. Some of the examined chicks revealed nephritis as swollen and pale kidneys, sometimes with tubules and ureters deposits with urates (Fig.3). In few cases, peticha of hemorrhage were seen on the mucosa of proventriculus with or without thickening of the musculature.

Clinical signs in replacement layers and breeders were less in severity, in the form of mild respiratory disease with coughing, sneezing and rales. Hens in production respiratory signs were unnoticed, but mainly decline in egg production was the common sign, which ranged between $8 \%$ and $30 \%$. The start of egg production in some flocks retarded 3-5 weeks with unpeaking to the standard, also accompanied with eggs of smaller size (about $5 \%$ ), soft -pale-shelled and misshapen eggs, and eggs with thin albumin (Figs 4 and 5). In majority of cases, production levels remains subnormal. In one recorded broiler breeder farm, fertility reduced to $77 \%$ ( $13 \%$ below standard). On necropsy of dead laying hens, oviduct length was reduced, and ovarian regression was noticed in some birds. Yolk material was often found in the abdominal cavity. One broiler breeder farm, exhibited pale and swollen deep pectoral muscles associated with gelatinous edema over the surface of the muscle. Bilateral myopathy affected both superficial and deep surface of the muscles (Figs. 6 and7).

Trials of isolation and identification of IBV: The influence of different IB virus strains on chicken embryos. Samples of trachea, lung, kidney, and cecal tonsil were taken from chickens were prepared for egg inoculation. For each sample to be examined, five to eight 9-to11-day-old (SPF) eggs were used. After 6 days of incubation, the eggs were examined for lesions indicative of IBV infection (dwarfing and curling of the embryo). The allantoic fluid was collected and tested for haemagglutination (HA) reaction with chicken red blood cells (CRBCs) (to exclude haemagglutinating agents). Uninoculated SPF eggs were always included as control of embryo size. Each sample was given four or five passage before being considered negative

Preliminary identification of suspected virus isolates as IB was done by an agar gel precipitation (AGP) test. The chorioallantoic membrane (CAM) were harvested from inoculated eggs for each sample at the level of $3^{\text {rd }}, 4^{\text {th }}$ and $5^{\text {th }}$ passage from both dead or chilled embryos, washed with sterile saline, grinded, freezed and thawed for several times, centrifuged at $3000 \mathrm{rpm}$ for 10 minutes and the supernatant fluid were examined by AGP test against positive precipitating IBV antiserum for evidence of IB infection.

The results revealed that 25 samples were positive for IB using in agar gel precipitation test (Table 3, 4).

In broiler farms incidence of the infection was recorded beyond 4 weeks of age (18.75\%), 
Table (1): Epidemiological sheet of the investigated chicken farms for IBV- infection.

\begin{tabular}{|c|c|c|c|c|c|c|c|c|c|}
\hline \multirow{2}{*}{$\begin{array}{c}\text { Serial } \\
\text { No. }\end{array}$} & \multirow{2}{*}{ Governorate } & \multirow{2}{*}{$\begin{array}{c}\text { Chicken } \\
\text { type }\end{array}$} & \multirow{2}{*}{ Breed } & \multirow{2}{*}{ Age } & \multirow{2}{*}{$\begin{array}{c}\text { House } \\
\text { Capacity }\end{array}$} & \multirow{2}{*}{$\begin{array}{l}\text { Housing } \\
\text { System }\end{array}$} & \multirow{2}{*}{$\begin{array}{l}\text { Vaccination } \\
\text { against IB }\end{array}$} & \multicolumn{2}{|c|}{ Problem } \\
\hline & & & & & & & & Signs & PM \\
\hline (1) & Giza & Layer & Lohman & $16 . \mathrm{w}$ & 14.000 & Cages & Yes (L) & Resp + Ent & Resp + Ent \\
\hline (2) & Menofia & Broiler & Arbor-Acres & $32 . \mathrm{d}$ & 5100 & Deep litter & Yes (L) & Resp & Resp \\
\hline (3) & Giza & Layer & Lohman & 16.w & 7.000 & Cages & Yes (L) & Resp + Ent & Resp + Ent \\
\hline (4) & Kalubia & Broiler & Hubbard & 39.d & 8.000 & Deep litter & Yes (L) & Resp & Resp \\
\hline (5) & Kafr-ElShikh & Broiler & Arbor-Acres & $36 . d$ & 4.800 & Deep litter & No & Resp + Ent & Resp + Ent \\
\hline (6) & Giza & Broiler & Hubbard & $41 . \mathrm{d}$ & 6000 & Deep litter & $\mathrm{Yes}(\mathrm{L})$ & Resp + Ent & Resp + Ent \\
\hline (7) & Dakahlia & Breeder & Cobb & 33.w & 7100 & Deep litter & Yes $(\mathrm{L}+\mathrm{I})$ & $\begin{array}{c}\text { Egg drop }(30 \%)+\downarrow \text { fert }+\downarrow \text { hatch } \\
+ \text { deformity }\end{array}$ & $\begin{array}{l}\text { Myopath }+ \text { Ren }+ \\
\text { peritonitis }\end{array}$ \\
\hline (8) & Kafr-ElShikh & Broiler & Arbor-Acres & $34 . d$ & 4800 & Deep litter & No & Resp & Resp \\
\hline (9) & Fayoum & Broiler & Avian & $32 . \mathrm{d}$ & 3600 & Deep litter & No & Resp & Resp + Ren \\
\hline (10) & Kalubia & Broiler & Arbor-Acres & $34 . d$ & 3400 & Deep litter & No & Resp & Resp \\
\hline (11) & Sharkia & Broiler & Hubbard & $34 . d$ & 7200 & Deep litter & No & Resp & Resp + Ren \\
\hline (12) & Sharkia & Layer & ISA & $18 . w$ & NR & Cages & Yes $(L+I)$ & Resp + Ent + Mort & Resp + Ent \\
\hline (13) & Menofia & Broiler & Hubbard & $25 . \mathrm{d}$ & 5300 & Deep litter & No & Resp + Ent & Resp + Ent + Ren \\
\hline (14) & Suez & Broiler & Hubbard & $25 . d$ & 6770 & Deep litter & No & Resp + Ent & \\
\hline (15) & Kafr-ElShikh & Broiler & Hubbard & $40 . d$ & 4000 & Deep litter & No & Resp & Resp + Ren \\
\hline (16) & Dakahlia & Broiler & Hubbard & $24 . \mathrm{d}$ & 6200 & Deep litter & Yes (L) & Resp + Ren & Resp + Ent \\
\hline (17) & Behira & Breeder & Cobb & 25.w & 20.000 & Deep litter & Yes $(L+I)$ & Egg drop $(8 \%)+$ egg deformity & genital \\
\hline (18) & Dakahlia & Broiler & Hubbard & $32 . \mathrm{d}$ & 5600 & Deep litter & Yes $(L)$ & Resp + Mort (7\%) & Resp \\
\hline (19) & Dakahlia & Broiler & Hubbard & $45 . \mathrm{d}$ & 7200 & Deep litter & No & Resp + Ent & Resp + Ent \\
\hline (20) & Giza & Breeder & Arbor-Acres & $69 . \mathrm{d}$ & 3000 & Deep litter & Yes (L) & Resp + Ent & Resp + Ent + Ren \\
\hline (21) & Suez & Broiler & Hubbard & $39 . \mathrm{d}$ & 8000 & Deep litter & Yes (L) & Resp + Ent & Resp + Ent \\
\hline (22) & Giza & Broiler & Avian & $39 . d$ & 6000 & Deep litter & Yes (L) & Resp + Ent & Resp + Ent \\
\hline (23) & Giza & Layer & Lohman & 41.w & 14.000 & Cages & Yes $(L+I)$ & Egg drop $(30 \%)$ & genital \\
\hline (24) & Gharbia & Layer & Lohman & 54.w & 14.000 & Cages & Yes $(\mathrm{L}+\mathrm{I})$ & Egg drop $(14 \%)+$ egg deformity & genital \\
\hline (25) & Dakahlia & Breeder & Aror-Acres & 34.w & 6000 & Deep litter & Yes $(L+I)$ & Egg drop + egg deformity & genital \\
\hline (26) & GIZA & Broiler & Arbor-Acres & $42 . \mathrm{d}$ & 45600 & Deep litter & No & Resp. & Resp. \\
\hline (27) & Kafr-El Shikh & Broiler & Arbor-Acres & 42.d & 5100 & Deep litter & No & Resp. & Resp. \\
\hline (28) & GIZA & Broiler & Arbor-Acres & 26.d & 4000 & Deep litter & No & Resp. & Resp. \\
\hline (29) & Kalubia & Broiler & Cobb & 37.d & 3500 & Deep litter & No & Resp. + Ent. & Resp + Ent \\
\hline (30) & Sharkia & Broiler & Hubbard & 26.d & 7000 & Deep litter & Yes (L) & Resp. & Resp. \\
\hline (31) & Ismalia & Broiler & Hubbard & $43 . d$ & 4500 & Deep litter & No & Resp. & Resp + Ren. \\
\hline (32) & Behera & Broiler & Baladi & $25 . d$ & 3500 & Deep litter & No & Resp. & Resp. \\
\hline (33) & Domiate & Broiler & Hubbard & $31 . d$ & 4800 & Deep litter & Yes (L) & Resp. + Ent. & Resp + Ent \\
\hline (34) & Alexandria & Layer & Bovans & 49.w & 20.000 & Cages & Yes $(L+I)$ & Egg drop $18 \%$ & genital \\
\hline (35) & GIZA & Breeder & Hubbard & 26.w & 20.000 & Deep litter & Yes $(\mathrm{L}+\mathrm{I})$ & Delay production & genital \\
\hline (36) & Dakahlia & Breeder & Hubbard & 34.w & 9.000 & Deep litter & Yes $(\mathrm{L}+\mathrm{I})$ & Egg drop 8\% & genital \\
\hline
\end{tabular}

$\mathrm{L}=$ Live vaccine. $\quad$ Resp $=$ Respiratory $\quad \mathrm{I}=$ Inactivated vaccine. $\quad$ Ent $=$ Enteric

$\downarrow$ fert $=$ reduce fertility. $\quad$ Myopath $=$ Myopathy $\quad \downarrow$ hatch $=$ reduce hatchability.

Mort $=$ Mortality $\quad$ NR : Not recorded. $\quad d=$ day $\quad w=$ week

Table (2): Collective sheet of the total 36 investigated chicken farms.

\begin{tabular}{|c|c|c|c|c|c|c|}
\hline & \multirow{3}{*}{ Item } & \multirow{3}{*}{ No } & \multicolumn{4}{|c|}{ History of vaccination } \\
\hline & & & \multicolumn{2}{|c|}{ Vaccinated } & \multicolumn{2}{|c|}{ Nonvaccinated } \\
\hline & & & No & $\%$ & No & $\%$ \\
\hline \multicolumn{2}{|c|}{ Governorates } & 13 & & & & \\
\hline \multicolumn{2}{|c|}{ Total examined farms } & 36 & 21 & 58.3 & 15 & 41.6 \\
\hline \multirow[t]{7}{*}{ Bird type, } & Broiler & 24 & 9 & 37.5 & 15 & 62.5 \\
\hline & Layer (total) & 6 & 6 & 100 & 0.0 & 0.0 \\
\hline & Layer (replacement) & 3 & 3 & 100 & 0.0 & 0.0 \\
\hline & Layer (laying) & 3 & 3 & 100 & 0.0 & 0.0 \\
\hline & Broiler breeder (total) & 6 & 6 & 100 & 0.0 & 0.0 \\
\hline & Broiler breeder (replacement) & 1 & 1 & 100 & 0.0 & 0.0 \\
\hline & Broiler breeder (laying) & 5 & 5 & 100 & 0.0 & 0.0 \\
\hline
\end{tabular}



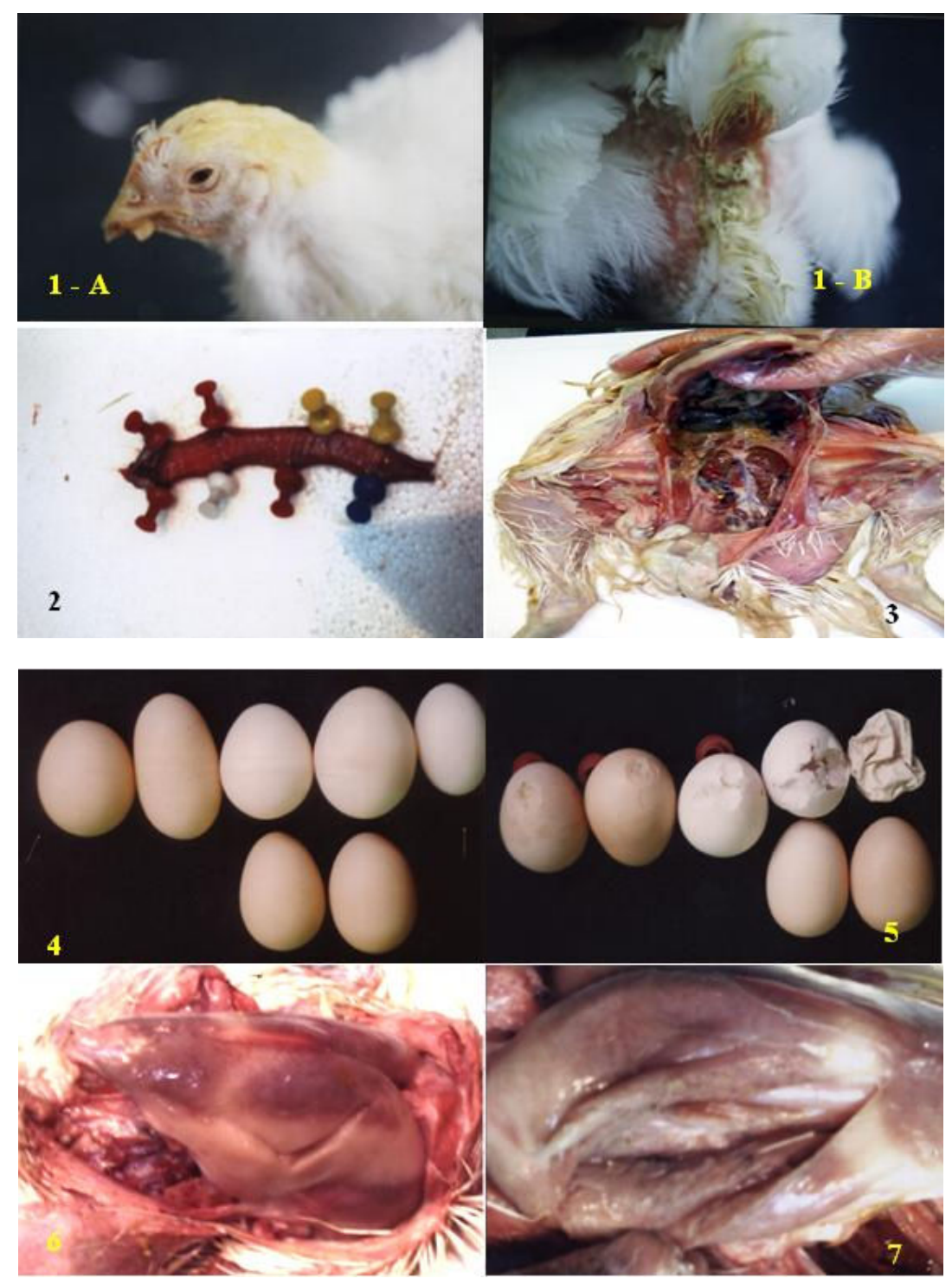

Field cases of natural infection with IB in broiler chickens.

Fig. (1 A and B): Chicken showing respiratory signs (congested eye and nasal discharge) and watery feces with soiled vent.

Fig. (2): Chicken mucosa of trachea with severe congestion.

Fig. (3): Congested lung, air saculitis, nephritis and deposition of uric acid in ureter.

Fig. (4): Abnormality of egg shape (misshapen and pale color) in naturally infected broiler breeder farm with IB. Fig. (5): Abnormality of egg shell showing variable soft shell in naturally infected broiler breeder farm with IB. Fig. (6): Field case of natural infection with IB in broiler breeder hen, had superficial pectoral myopathy.

Fig. (7): Field case of natural infection with IB in broiler breeder hen, showing deep pectoral myopathy.

at 5 weeks $(37.5 \%)$, at 6 weeks $(37.5 \%)$ and at 7 weeks (6.25\%) (table5). Embryonic mortality within 2-6 days pi during five embryonic passage (table 6 and 7) revealed that some IBV field isolates were not embryo adapted and did not cause death or lesions in the first passage, therefore 5 passages were made before virus isolation attempt is considered to be negative.

Adaptation of IBV-field isolates to egg embryos by further passages up to the $5^{\text {th }}$ passage, was associated with dwarfing as judged by reduction in percentage of infected embryonic weight by approximately $25 \%$ less than of noninfected embryo weight (table 8), hemorrhage cutenous lesions, curled into spherical form with feet deformed and compressed over the head. Some embryos showed mesonephrous containing urates and thickened amnion covering the stunted embryos.

Trials of isolation and identification of IBV. The influence of different IB virus strains on chicken embryos. Samples of trachea, lung, kidney, and cecal tonsil were taken from chickens were prepared for egg inoculation. For 
each sample to be examined, five to eight 9-to11-day-old (SPF) eggs were used. After 6 days of incubation, the eggs were examined for lesions indicative of IBV infection (dwarfing and curling of the embryo). The allantoic fluid was collected and tested for haemagglutination (HA) reaction with chicken red blood cells (CRBCs) (to exclude haemagglutinating agents). Uninoculated SPF eggs were always included as control of embryo size. Each sample was given four or five passage before being considered negative

Preliminary identification of suspected virus isolates as IB was done by an agar gel precipitation (AGP) test. The chorioallantoic membrane (CAM) were harvested from inoculated eggs for each sample at the level of $3^{\text {rd }}, 4^{\text {th }}$ and $5^{\text {th }}$ passage from both dead or chilled embryos, washed with sterile saline, grinded, freezed and thawed for several times, centrifuged at $3000 \mathrm{rpm}$ for 10 minutes and the supernatant fluid were examined by AGP test against positive precipitating IBV antiserum for evidence of IB infection.

The results revealed that 25 samples were positive for IB using in agar gel precipitation test (Table3 and 4).

In broiler farms incidence of the infection was recorded beyond 4 weeks of age $(18.75 \%)$, at 5 weeks $(37.5 \%)$, at 6 weeks $(37.5 \%)$ and at 7 weeks (6.25\%) (Table5).

Embryonic mortality within 2-6 days pi during five embryonic passages (Table 6 and 7) revealed that some IBV field isolates were not embryo adapted and did not cause death or lesions in the first passage, therefore 5 passages were made before virus isolation attempt is considered to be negative.

Adaptation of IBV-field isolates to egg embryos by further passages up to the $5^{\text {th }}$ passage, was associated with dwarfing as judged by reduction in percentage of infected embryonic weight by approximately $25 \%$ less than of non- infected embryo weight (Table 8), hemorrhage cutenous lesions, curled into spherical form with feet deformed and compressed over the head. Some embryos showed mesonephrous containing urates and thickened amnion covering the stunted embryos.

The influence of different strains IB virus on chicken embryo kidney cells (CEK). Twenty IBV isolates originated from choriallantoic fluids harvested from the $5^{\text {th }}$ egg embryo passage were used as inoculum (Table 8). Focal cytopathic effect (CPE) started to observe 24-48 h pi (under inverted microscope in unstained culture), followed by extensive CPE on the $3^{\text {rd }}$ day pi, but were seen in later passages after 24 hours incubation. These gradual changes are described as follows: 1.Foci of refractile round cells and occasional syncytia (Fig.12). 2. The affected cells became detached from the monolayer and tended to aggregate in clumps that floated free in the nutrient medium. 3.Appearance of porous large area distinctly demarcated from the rest of the cells. (Fig.13-17).

The influence of different strains IB virus on chicken embryo kidney cells (CEK). Twenty IBV isolates originated from choriallantoic fluids harvested from the $5^{\text {th }}$ egg embryo passage were used as inoculum (Table 8). Focal cyto-pathic effect (CPE) started to observe 24-48 hours pi (under inverted microscope in unstained culture), followed by extensive CPE on the $3^{\text {rd }}$ day pi, but were seen in later passages after 24 hours incubation. These gradual changes are described as follows: 1.Foci of refractile round cells and occasional syncytia (Fig.12). 2. The affected cells became detached from the monolayer and tended to aggregate in clumps that floated free in the nutrient medium. 3.Appearance of porous large area distinctly demarcated from the rest of the cells. (Fig.13-17).

\section{Discussion}

Infectious bronchitis (IB) virus, first described in 1930 (Schalk and Hawn, 1931), continues to be a major cause of disease in chickens of all ages and types all over the world (Anon, 1988, 1991). The disease is prevalent in all countries with an intensive poultry industry, with the incidence of infection approaching $100 \%$ in most locations (Ignjatovic and Sapats, 2000). The disease is primarily a respiratory infection of chickens. Nevertheless, three clinical manifistations are generally observed in the field, namely: respiratory disease, reproductive disorders and nephritis (Cavanagh and Naqi, 1997; McMartin, 1993). Concerning the prevelance of IB outbreaks in some locations in Egypt, in the present investigations, examination of 36 chicken farms distributed in 13 governorates, representating broilers, layers and broiler breeder farms revealed that the IBV is prevalent in Egypt, since the initial description 
Table (3): Collective results of isolation and identification of IBV by egg inoculation.

\begin{tabular}{lccc}
\hline Type & Total No. examined farms & No. of Farms positive for IBV isolation & \% \\
\hline Broiler & 24 & 16 & 66.66 \\
Layer & 6 & 5 & 83.3 \\
Breeder & 6 & 4 & 66.66 \\
\hline
\end{tabular}

Table (4): Incidence of IBV infection in 16 positive broiler chicken farms in relation to age.

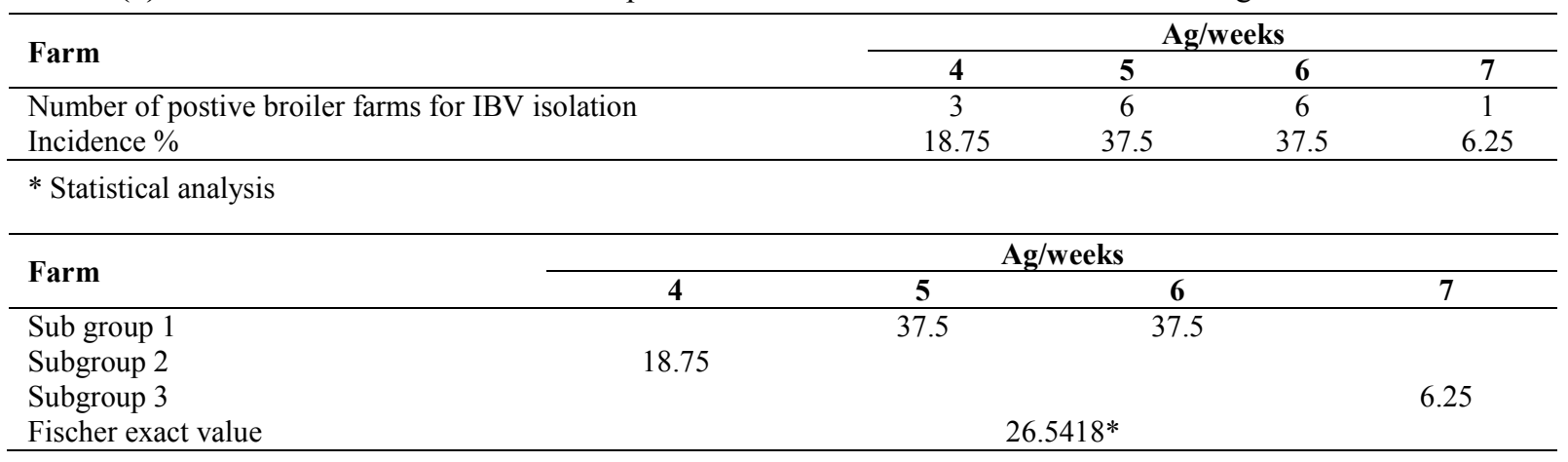

* Significant at $\mathrm{p}<0.05$ using Fischer Exact probability test for comparative of means.

Data significant divided into three significant subgroups where subgroup 1 (5 and 6 weeks), significant different then subgroup 2 ( $4^{\text {th }}$ week) and then those of subgroup 3 ( $7^{\text {th }}$ week) using Duncan Multiples range test for comparative of means.

Table (5): Percentage of Embryonic lethality followign IBV isolates inoculation of 9-10 days SPF egg embryos during 5 passages.

\begin{tabular}{|c|c|c|c|c|c|c|c|c|c|}
\hline \multirow{2}{*}{$\begin{array}{l}\text { Isolate } \\
\text { Code }\end{array}$} & \multirow{2}{*}{$\begin{array}{c}\text { Chicken } \\
\text { type }\end{array}$} & \multirow{2}{*}{ Breed } & \multirow{2}{*}{ Age } & \multirow{2}{*}{$\begin{array}{c}\text { Vaccination } \\
\text { against IB }\end{array}$} & \multicolumn{5}{|c|}{ Embryo lethality \%/passages } \\
\hline & & & & & p.1 & p.2 & p.3 & p.4 & p.5 \\
\hline 1 & Layer & Lohman & $16 . \mathrm{w}$ & Yes (L) & 0 & 0 & 0 & 12.7 & 62.5 \\
\hline 2 & Broiler & Arbor-Acres & 32.d & Yes (L) & 0 & 0 & 50 & 50 & 62.5 \\
\hline 3 & Layer & Lohman & 16.w & Yes (L) & 0 & 25 & 0 & 37.5 & 71.5 \\
\hline 4 & Broiler & Hubbard & $39 . d$ & Yes (L) & 0 & 0 & 40 & 71.5 & 100 \\
\hline 5 & Broiler & Arbor-Acres & $36 . d$ & No & 0 & 0 & 0 & 28.5 & 57 \\
\hline 6 & Broiler & Hubbard & 41.d & Yes (L) & 20 & 25 & 0 & 16.6 & 50 \\
\hline 7 & Breeder & Cobb & 33.w & Yes $(\mathrm{L}+\mathrm{I})$ & 20 & 0 & 0 & 62.5 & 100 \\
\hline 8 & Broiler & Arbor - Acres & $34 . d$ & No & 0 & 20 & 25 & 0 & 0 \\
\hline 9 & Broiler & Avian & 32.d & No & 0 & 20 & 40 & 100 & 100 \\
\hline 10 & Broiler & Arbor-Acres & $34 . d$ & No & 25 & 0 & 0 & 28.5 & 71.4 \\
\hline 11 & Broiler & Hubbard & $34 . d$ & No & 0 & 100 & 100 & 100 & 100 \\
\hline 12 & Layer & ISA & $18 . \mathrm{w}$ & Yes $(\mathrm{L}+\mathrm{I})$ & 0 & 0 & 0 & 0 & 57 \\
\hline 13 & Broiler & Hubbard & $25 . d$ & No & 0 & 0 & 20 & 66.6 & 100 \\
\hline 14 & Broiler & Hubbard & $25 . d$ & No & 0 & 25 & 50 & 100 & 100 \\
\hline 15 & Broiler & Hubbard & $40 . d$ & No & 0 & 80 & 60 & 62.5 & 43 \\
\hline 16 & Broiler & Hubbard & $24 . d$ & Yes (L) & 20 & 75 & 0 & 50 & 0 \\
\hline 17 & Breeder & Cobb & $25 . w$ & Yes $(\mathrm{L}+\mathrm{I})$ & 0 & 0 & 50 & 43 & 100 \\
\hline 18 & Broiler & Hubbard & $32 . d$ & Yes (L) & 0 & 20 & 66.6 & 57 & 83 \\
\hline 19 & Broiler & Hubbard & $45 . d$ & No & 0 & 40 & 0 & 25 & 43 \\
\hline 20 & Breeder & Arbor-Acres & $69 . d$ & Yes (L) & 20 & 0 & 25 & 50 & 100 \\
\hline 21 & Broiler & Hubbard & $39 . d$ & Yes (L) & 0 & 0 & 20 & 37.5 & 12.5 \\
\hline 22 & Broiler & Avian & $39 . d$ & Yes (L) & 0 & 0 & 25 & 100 & 100 \\
\hline 23 & Layer & Lohman & 41.w & Yes $(\mathrm{L}+\mathrm{I})$ & 0 & 0 & 50 & 71.4 & 100 \\
\hline 24 & Layer & Lohman & $54 . \mathrm{w}$ & Yes $(\mathrm{L}+\mathrm{I})$ & 0 & 60 & 100 & 100 & 100 \\
\hline 25 & Breeder & Arbor-Acres & $34 . \mathrm{w}$ & Yes $(\mathrm{L}+\mathrm{I})$ & 25 & 0 & 0 & 71.4 & 71.4 \\
\hline
\end{tabular}

$\mathrm{W}=$ week $\quad \mathrm{d}=$ day $\quad \mathrm{L}=$ Live Vaccine $\quad \mathrm{I}=$ Inactivated vaccine

Dead embryos within 24 hours post inoculation were discarded from calculation. 
Table (6): Collective mean percentage of embryonic lethality following 25-IBV inoculation of 9-10 days SPF egg embryos during 5 passages.

\begin{tabular}{cccccc}
\hline \multirow{2}{*}{ IBV isolate numbers } & \multicolumn{5}{c}{ Embryonic lethality \%/ Passages } \\
\cline { 2 - 6 } & p.1 & p.2 & p.3 & p.4 & p.5 \\
\hline 25 & 5.2 & 19.6 & 28.86 & 53.68 & 71.39 \\
\hline
\end{tabular}

$\mathrm{p}=$ passage level

Table (7): Collective results of embyronic weight reudction \% of survived embryos for 25 IBV isolates at the level of fourth and fifth passage.

\begin{tabular}{|c|c|c|c|c|c|c|c|}
\hline \multirow{2}{*}{$\begin{array}{l}\text { Isolate } \\
\text { Code }\end{array}$} & \multicolumn{2}{|c|}{ Embryo weight reduction \% } & \multirow{2}{*}{ Dwarfing } & \multirow{2}{*}{$\begin{array}{c}\text { Isolate } \\
\text { Code }\end{array}$} & \multicolumn{2}{|c|}{ Embryonic weight reduction \% } & \multirow{2}{*}{ Dwarfing } \\
\hline & p.4 & p.5 & & & p.4 & p.5 & \\
\hline 1 & 9.2 & 19.2 & Neg. & 14 & 5.7 & 7.3 & Neg. \\
\hline 2 & 15.5 & 18.3 & Neg. & 15 & 6.9 & 8.2 & Neg. \\
\hline 3 & 5.3 & 19.5 & Neg. & 16 & NR & 56.6 & Post. \\
\hline 4 & 17 & 24.5 & Post. & 17 & 22.5 & 39.3 & Post. \\
\hline 5 & 16.04 & 24.5 & Post. & 18 & 13.2 & 21.4 & Neg. \\
\hline 6 & 9.2 & 13.1 & Neg. & 19 & 19.3 & 22.8 & Neg. \\
\hline 7 & 15.8 & 29.7 & Post. & 20 & 10.2 & 9.5 & Neg. \\
\hline 8 & 15.6 & 21.3 & Neg. & 21 & 14.3 & 20.6 & Neg. \\
\hline 9 & 23.6 & 30.8 & Post. & 22 & 5.2 & 12.9 & Neg. \\
\hline 10 & 7.6 & 17.6 & Neg. & 23 & 24.0 & 25.6 & Post. \\
\hline 11 & 23.8 & 30.4 & Post. & 24 & 28 & 35.9 & Post. \\
\hline 12 & 11.8 & 14.3 & Neg. & 25 & 7.6 & 17.6 & Neg. \\
\hline 13 & 8.6 & 3.8 & Neg. & Mean & $13.99+1.38$ & $21.78+2.32$ & \\
\hline
\end{tabular}

- Embryo weight reduction $\%=$ A weight differential of 25 percent or more between infected and normal embryos of the same age may be considered evidence of viral infection, (Anon, 1963).

- Embryonic reduction \% = Mean weight of inoculated embryos $\mathrm{x} 100$

Mean weight of unioculated (control) embryos

Table (8): Results of inoculation of IBV isolates in chicken embryo kidney (CEK) cells.

\begin{tabular}{|c|c|c|c|c|}
\hline \multirow{2}{*}{ Isolate Code } & \multicolumn{4}{|c|}{ Cytopathic effect*/Passage No. } \\
\hline & Passage-1 & Passage-2 & Passage 3 & Passage 4 \\
\hline 1 & + & + & ++ & +++ \\
\hline 2 & $(-)$ & + & ++ & +++ \\
\hline 3 & + & ++ & +++ & +++ \\
\hline 4 & + & ++ & +++ & +++ \\
\hline 5 & $(-)$ & + & ++ & +++ \\
\hline 6 & + & + & ++ & +++ \\
\hline 7 & NT & NT & NT & NT \\
\hline 8 & + & ++ & +++ & +++ \\
\hline 9 & $(-)$ & + & ++ & +++ \\
\hline 10 & $(-)$ & + & ++ & +++ \\
\hline 11 & + & ++ & +++ & +++ \\
\hline 12 & NT & NT & NT & NT \\
\hline 13 & $(-)$ & + & ++ & +++ \\
\hline 14 & NT & NT & NT & NT \\
\hline 15 & + & ++ & ++ & +++ \\
\hline 16 & + & ++ & ++ & +++ \\
\hline 17 & + & + & ++ & +++ \\
\hline 18 & + & ++ & +++ & +++ \\
\hline 19 & $(-)$ & + & ++ & +++ \\
\hline 20 & NT & NT & NT & NT \\
\hline 21 & + & ++ & +++ & +++ \\
\hline 22 & NT & NT & NT & NT \\
\hline 23 & + & +++ & +++ & +++ \\
\hline 24 & + & ++ & +++ & +++ \\
\hline 25 & + & ++ & ++ & +++ \\
\hline
\end{tabular}

- $\quad \mathrm{NT}=$ not tested. $\quad *$ inverted microscopy examined in unstained culture.

- $\quad+=$ Focal involvement. $\quad++=$ partial involvement. $\quad+++=$ Extnesive involvement. 

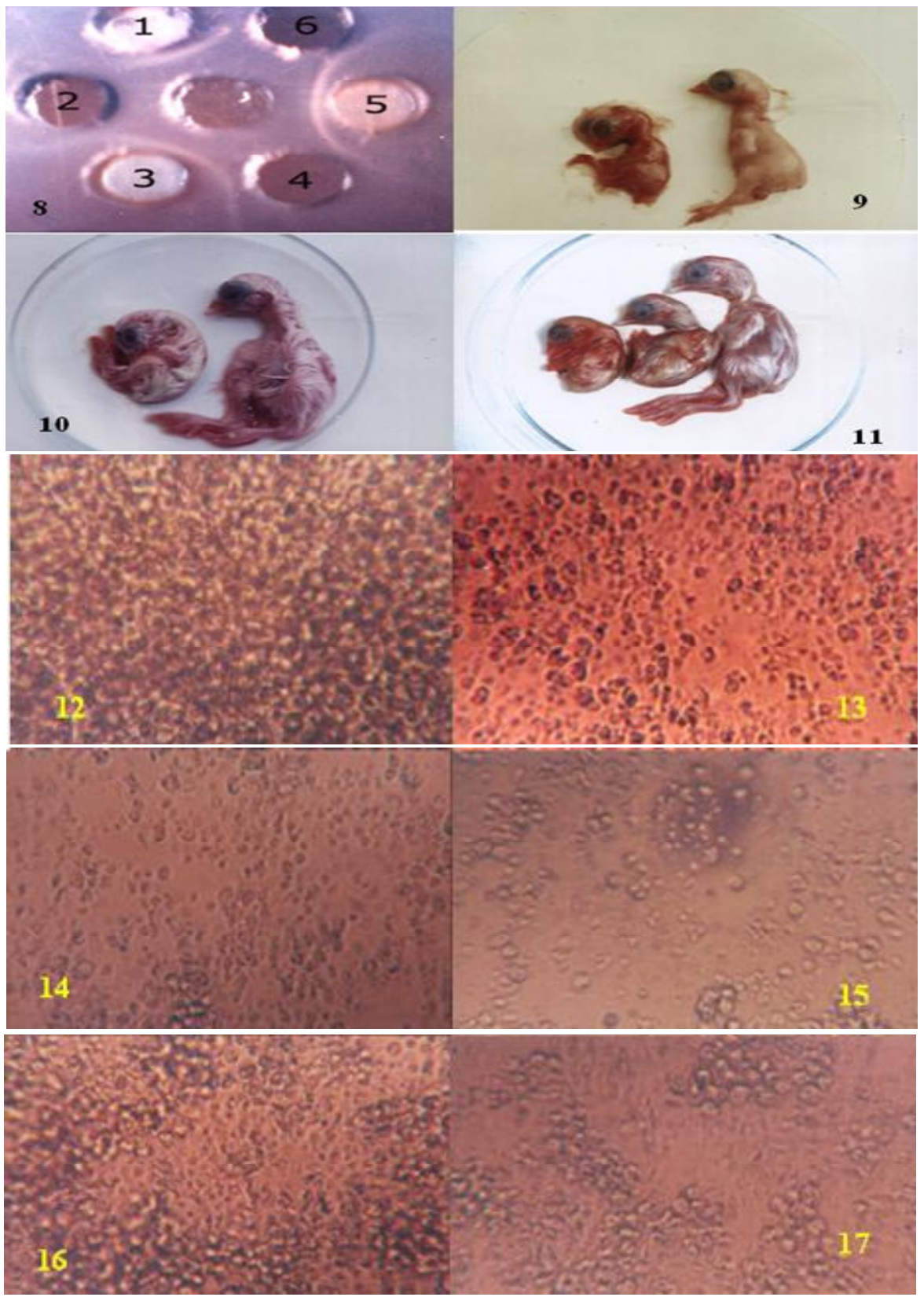

Fig. (8): Laboratory identification of field isolates of IBV using AGPT. Central well contain positive precipitating serum against IBV, wells 2, 4, 6 are empty wells 1 and 3 contain CAM homogenates of tested samples, and well 5 contain positive standard precipitating IBV antigen. Precipitating lines obtained with tested (1 and 3 ) and reference (5) antigens.

Fig. (9): Lethal IBV showing stunted SPF chick embryo $72 \mathrm{~h}$ pi at the level of the $4^{\text {th }}$ embryonic passage (left) as compared with non infected control (right) of the same age.

Fig. (10): Non lethal IBV showing SPF chick embryo with stunted, hemorrhagic, feet deformity at 18 days of age (left) as compared with non infected control (right) of the same age.

Fig. (11): Non lethal IBV showing SPF embryo with curling, stunting, hemorrhages and feet deformity at 18 days of age at the level of the fourth embryonic passage (left) as compared with non infected control (right) of the same age.

Fig. (12): Control non-infected monolayer of CEKC, $48 \mathrm{hr}$ after culturing.

Fig. (13): Characteristic CPE produced by IBV at passage level-2. Affected cells detached from monolayer and tend to aggregate in clumps (unstained culture).

Fig. (14): Characteristic CPE produced by IBV at passage level-3. Increased areas of detached cells and tend to aggregate in clumps (unstained culture).

Fig. (15): Characteristic CPE produced by IBV at passage level-2. Affected cells became refractile rounded (unstained culture).

Fig. (16): Characteristic CPE produced by IBV at passage level-3. Porous large area distinctly demarcated from the rest of cells (unstained culture).

Fig. (17): Characteristic CPE produced by IBV. Isolated areas of detached cells fuse together and cause coallesive areas of detached cells (unstained culture). 
Table (9): Collective results "incidence percentage" of CPE in CEK-cell culture.

\begin{tabular}{|c|c|c|c|c|c|c|c|c|}
\hline \multirow{3}{*}{$\begin{array}{l}\text { No. of examined } \\
\text { samples }\end{array}$} & \multicolumn{8}{|c|}{ No. and percentage of CPE } \\
\hline & \multicolumn{2}{|c|}{ Pass.1 } & \multicolumn{2}{|c|}{ Pass.2 } & \multicolumn{2}{|c|}{ Pass.3 } & \multicolumn{2}{|c|}{ Pass.4 } \\
\hline & Post. & $\%$ & Post. & $\%$ & Post. & $\%$ & Post. & $\%$ \\
\hline 20 & 14 & 70 & 20 & 100 & 20 & 100 & 20 & 100 \\
\hline Post. $=$ Positive & & & Pas & age. & & & & umbe \\
\hline
\end{tabular}

and isolation of the virus (Ahmed, 1954; Eissa et al., 1963; Ahmed, 1964; Amin and Mustagger, 1977 and El-Kady, (1989)). Occurrence of the disease in unvaccinated 9 broiler farms out of 24 examined broiler farms (37.5\%), tables ( 1 and 2), was expected finding due to the highly contagious nature of the disease (Cavanagh and Naqi, 2003) and the method of spread is airborne or mechanical transmission between birds, houses and farms. Airborne transmission is via aerosol and occurs readily between birds kept at a distance over 1.5 meters. Prevailing winds might also contribute to spread between farms that are separated by a distance of as much as 1,200 meter (Cumming, 1970). On the other hand, occurrence of the disease in 7 vaccinated broiler farms $(29.16 \%)$ and 5 vaccinated layer farms and (4) vacinnated broiler breeder farms, was also expected, based on the presence of large number of antigenic serotypes (Cook and Huggins, 1986; Gelb et al., 1991; Gubillos et al., 1991) and emerge of new IBV variants with nephropathogenic property of most of them was the characteristic of the recent history of the disease in Egypt in the last six years by many investigatores (El-Sisi and Eid, 2000; Lebdah et al., 2004; Sultan et al., 2004). Also, the long life span of layers and broiler breeders is favrable for the evolution of new serotypes as well as, immune selective pressure produced by intensive live and inactivated vaccination, maintenance of multi-age flocks for contnual production, periodic introduction of pullets, infrequent clean out and disinfection of the premises, and the recycling of the virus in the flocks resulting in great apportunity for infections and spreading of the disease (Gelb et al., 1991 and Gelb et al., 1997). This speculation was the main objective of the present investigations.

Recording of the respiratory form of the disease as the most observed syndrome, mostly in broiler farms beyond 4 weeks of age and to a less extent in replacement layer and breeder and laying hens were similar to those described by (McMartin, 1993; Cavanagh and Nagi, 1997). Occurrence of other clinical signs and necropsy, resembled those reported by several reports including wet eyes, swollen sinuses; reduced feed consumption and body weight, varying mortality (Hofstad, 1984), wet droppings (Bumstead et al., 1989), declines in egg production, quality abnormality of eggs and hatchability (Cook et al., 1987), breeder myopathy of pectoral muscles (Parsons et al., 1992), respiratory lesions (Hofstad, 1984), renal lesions (Gough et al., 1992) and genital lesions (Hofstad, 1984), swelling of glandular stomach (Wang et al., 1998) and haemorrhagic ulceration of the glandular stomach. Conclusively, the present study confirms that the epidemiology of IB in Egyptian chicken farms is a continous problem, and none of the countries which have an intensive poultry industry are free from IBV. Although attempts have been made, at the regional level, to keep flocks free from IBV, but without successful results. Given the highly infectious nature of the virus, even the strictest preventative measures are sometimes not sufficient (Ignjatovic and Sapats, 2000). Under normal flock management with "all-in/all-out" operations, cleaning and disinfections between batches limited the level of infection to the minimum. However; exclusion of IBV has not been achieved through such measures (Ignjatovic and Sapats, 2000).

Primary isolation of IBV, based on inoculation in 9-11 day old SPF chicken embryo (Anon, 1963; Gelb and Jackwood, 1998) was adopted which could cover three important objectives. (1) Isolation and identification of IBV. (2) Determination of virus lethality. (3) Recording embryo gross abnormality (stunting and dwarfing effect of the virus).

The tissue tropism of IBV strains seemed to be wide and variable (Lucio and Fabricant, 1990). The presence of the IBV in the respiratory and urogenital tract of chickens could be well documented. Different strains of IBV had been isolated from spleen, feaces, cecal tonsils, cloacal content, semen, eggs, bursa and oesphagous as reported by (Lucio and Fabricant, 1990). Generally, it has been assumed that the 
cecal tonsils and kidnys could be considered an important sites for the persistance of IBV, as the virus has been recovered from these tissues for a prolonged period as also mentioned by Alexander et al.,(1978) and we think that to avoid false negative results the specimens taken for IBV isolation must include trachea, lung, kidney, and cecal tonsils as also mentioned by Jose et al.,(2000). On primary isolation, gross pathological alterations of the embryo were employed as evidence of viral activity. While embryo mortality was not a constant finding on intial passage as also mentioned by Cunningham and Jones, (1953). In some cases as many as 3 4 serial passages may be necessary before detection of IBV infection, based on embryo death or lesions and the serial passage of IBV in eggs was accompanied by an increase in virulence for embryos (Bijlegna, 1960; Anon, 1963). Therefore, five passages were performed in the present study before the virus-isolation attempt was considered as negative.

Using of CAM homogenate of inoculated embryos in agar gel precipitation (AGP) test against positive reference precipitating sera gave specific positive precipitin band(s) in 25 IBV isolates (Table 3), as also correspond to the findings of Woernle, (1966); Hofstad, (1981); who concluded that the AGP test was suitable and specific for identifying field isolates of IBV as it could detect group specific antigen common to all IBV strains and serotypes. Deaths of few embryos at initial first passage $(5.2 \%)$, followed by increasing to $19.6 \%, 28.8 \%, 53.6 \%$ and $71.3 \%$ on subsequent $2^{\text {nd }}, 3^{\text {rd }}, 4^{\text {th }}$ and $5^{\text {th }}$ passages tables (4 and 5), accompanied by embryos dwarfing which was more evidence at level of $5^{\text {th }}$ passage ( 9 out of 25 isolates "36\%") (Table 6 $\& 7)$. These findings was explained as that the serial passages of IBV in egg embryos was accompanied by an increase in virulence for embryos (Anon, 1963; Cavanagh and Naqi, 2003), although some IBV isolates did not cause dwarfing of the inoculated embryos after serial passage (Clark et al., 1972). Among the alterations which were considered most typical of IBV infection were weak living embryos, curling of embryos with feet deformed compressed over the head, and presence of urates in the persistent mesonephron were also reported by (Anon 1963; OIE, 1996; Cavanagh and Naqi, 1997). For primary isolation of IBV, chicken kidney cell culture was not recommended, because the virus required adaptation in embryonating eggs before its cultivation in cell culture (Gelb and Jackwood, 1998; Cavanagh and Naqi, 2003). For this, 20 IBV strains previously adapted to propagate in embryonated eggs up to five passages were used as inoculum in chicken embryo kidney (CEK) cell, for four blind passages. Results of tables $8 \& 9$ and Figs. $12-17$, revealed that all the isolated IBV, were adapted and grew in CEK cell culture. Six isolates $(30 \%)$ did not induce characteristic $\mathrm{CPE}$ in the first passage, while the other 16 isolates $(70 \%)$ could induce characteristic CPE. By repassage of 20 examined isolates in CEK cells all were successfully adapted and CPE developed at $100 \%, 100 \%, 100 \%$ at the levels $2^{\text {nd }}, 3^{\text {rd }}$ and $4^{\text {th }}$ passage; respectively. Cytopathic changes produced by the IBV strains were granularity and vacuolization of the cytoplasm. The affected cells became detatched from the monolayer and tend to aggregate in clumps that floated free in the nutrient medium. Appearance of porous large area distinctly demarcated from the rest of the cells. Multinucleated giant cells (syncytia) were not numerous in early passages, but were seen in later passages of all strains when examined after 24 hours incubation, these findings were similar to those reported previously (Hopkins, 1974).

\section{References}

Ahmed, H.N. (1954): Incidence and treatment of some infectious viral respiratory diseases of poultry in Egypt. Ph.D.Thesis, Fac. Vet. Med. Cairo University, Giza, Egypt. Ahmed, A.A.S. (1964): Infekiose Bronchitis des Huhnes in Aegypten. Berl. Munch. Tieraztl. Wschr., 77: 481-484.

Alexander, D.J.; Gough R.E and Pattison, M. (1978): A long-term study of the pathogenesis of infection of fowl with three strains of avian infectious bronchitis virus. Res. Vet. Sci. 24: 228-233.

Amin, Afaf and Mostageer, M. (1977): A preliminary report on an avian infectious bronchitis virus strain associated with nephritis-nephrosis Syndrome in chickens. J. Egypt. Vet. Med. Ass., 37 (2): 71-79.

Anon, (1963): Infectious bronchitis of chickens. In: Methods for the examination of poultry biologics. National Academy of Science: 60-66.

Anon, (1988): Proceedings of the first International Symposium on Infectious Bronchitis, Rauischholzhausen, Germany.

Anon, (1991): proceedings of the Second International Symposium on Infectious Bronchitis, Rouischholzhausen Germany.

Bijlenga, G. (1960): Investigation on the activity of living vaccine against infectious bronchitis of chickens with an drinking water. Doctor thesis, Faculty of Veterinary Medicine, Berne, Switzerland.Breukelen : G.Van.Dijk.

Bumstead, N.; Huggins, M.B. and Cook, J. K. (1989): Genetic differences in susceptibility to a mixture of avian infectious branchitis virus and Escherichia Coli. Br. Poult. Sci. 30: 39-48.

embryonated egg adapted autogenous virus strain applied in 


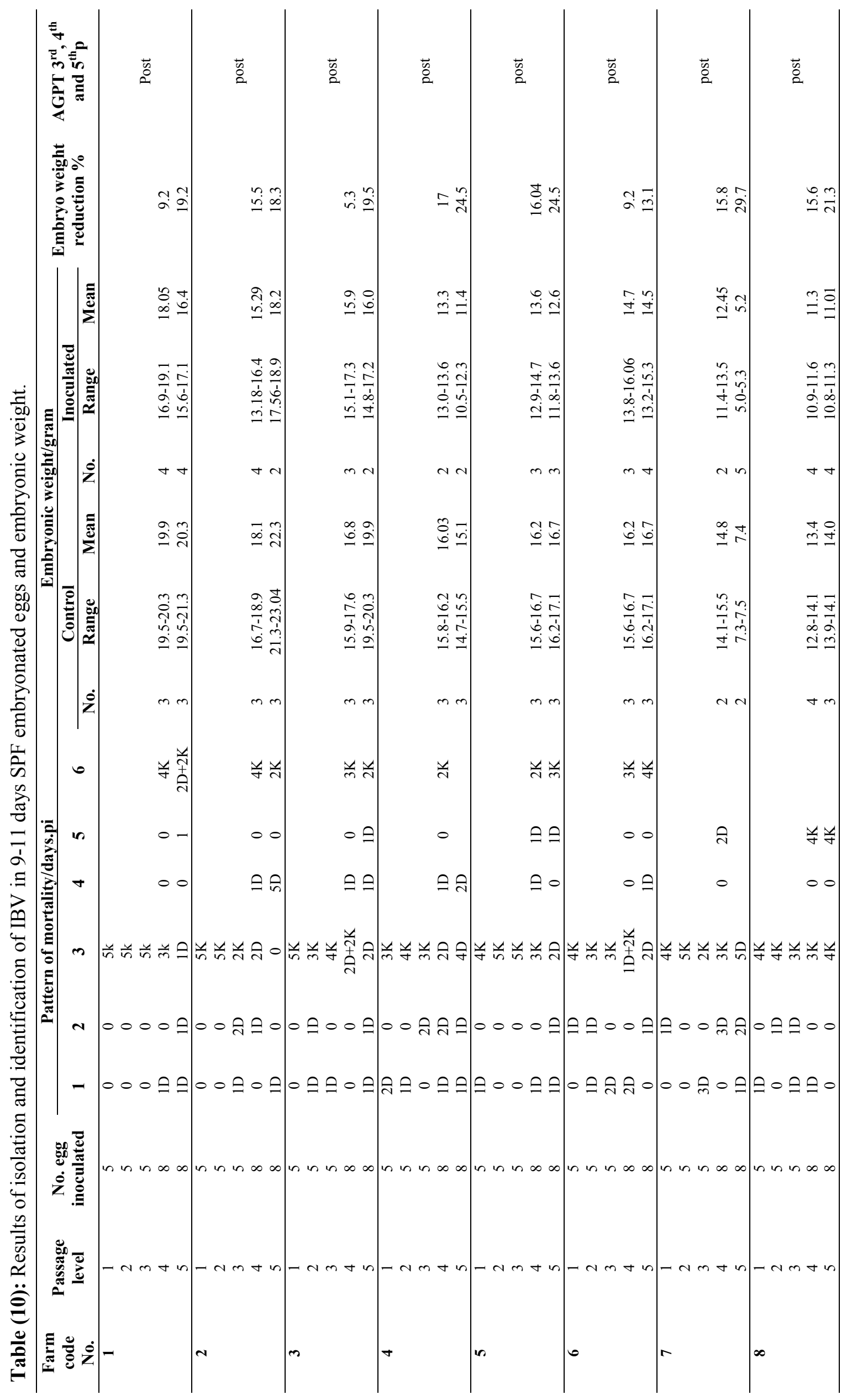




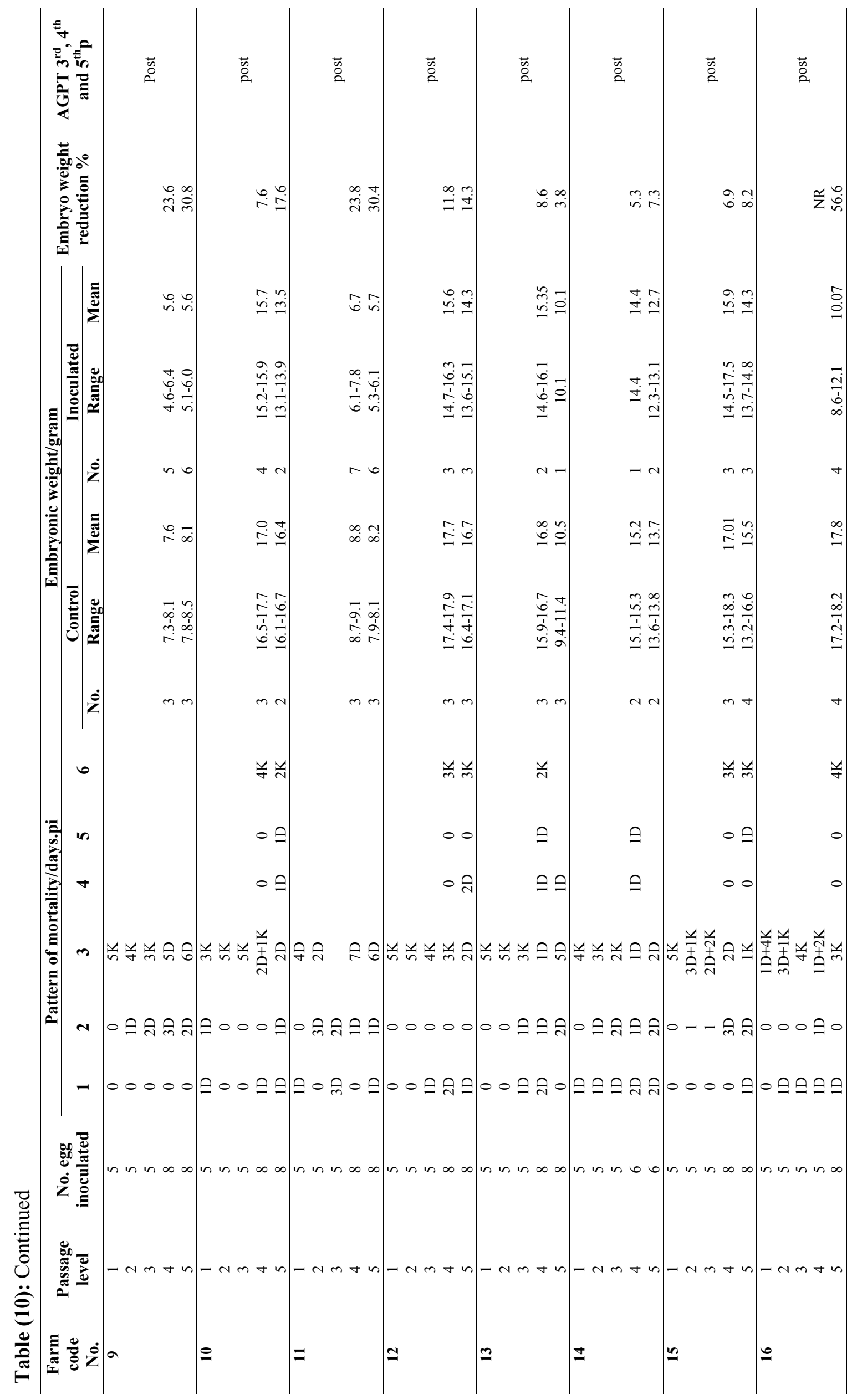




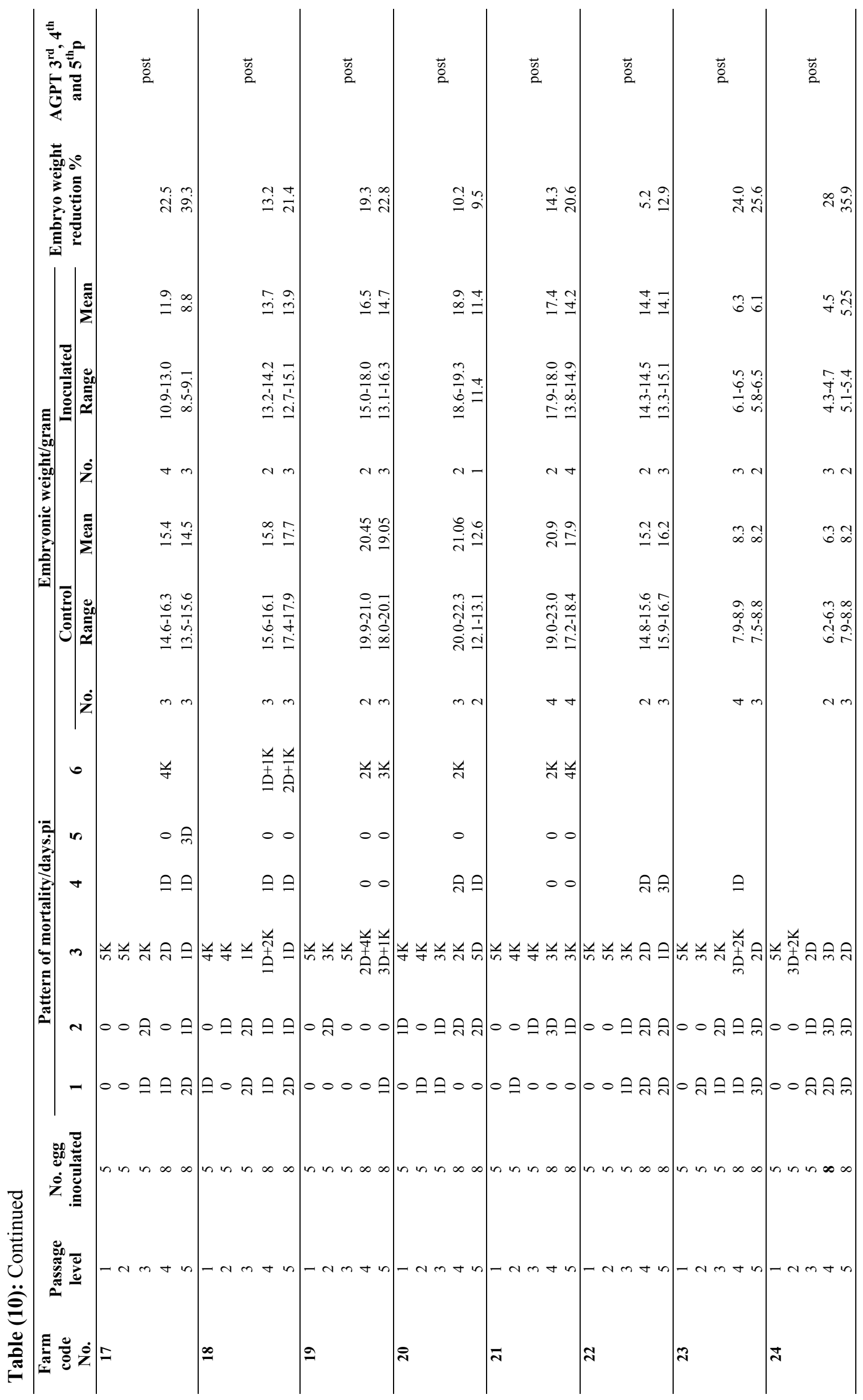




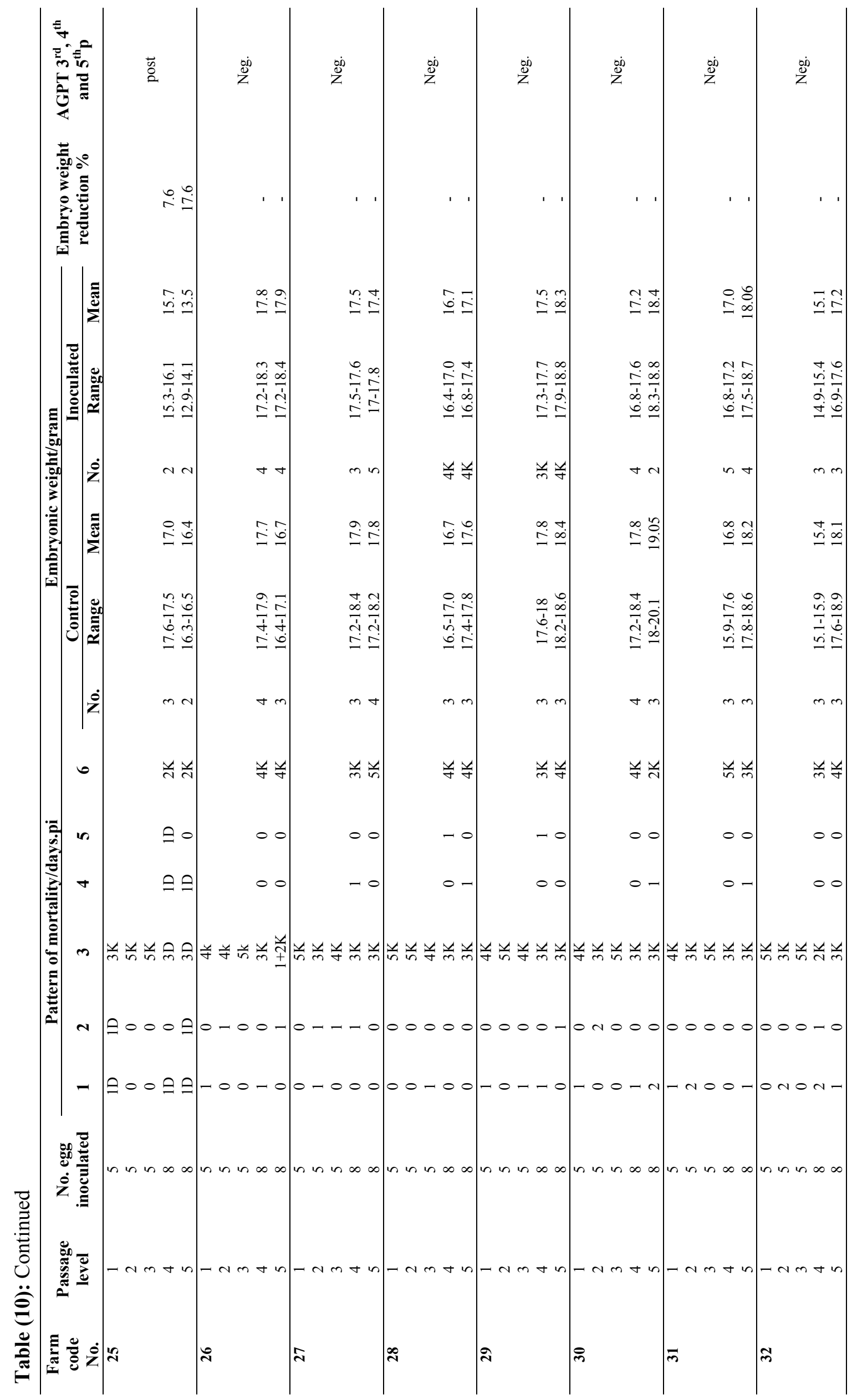




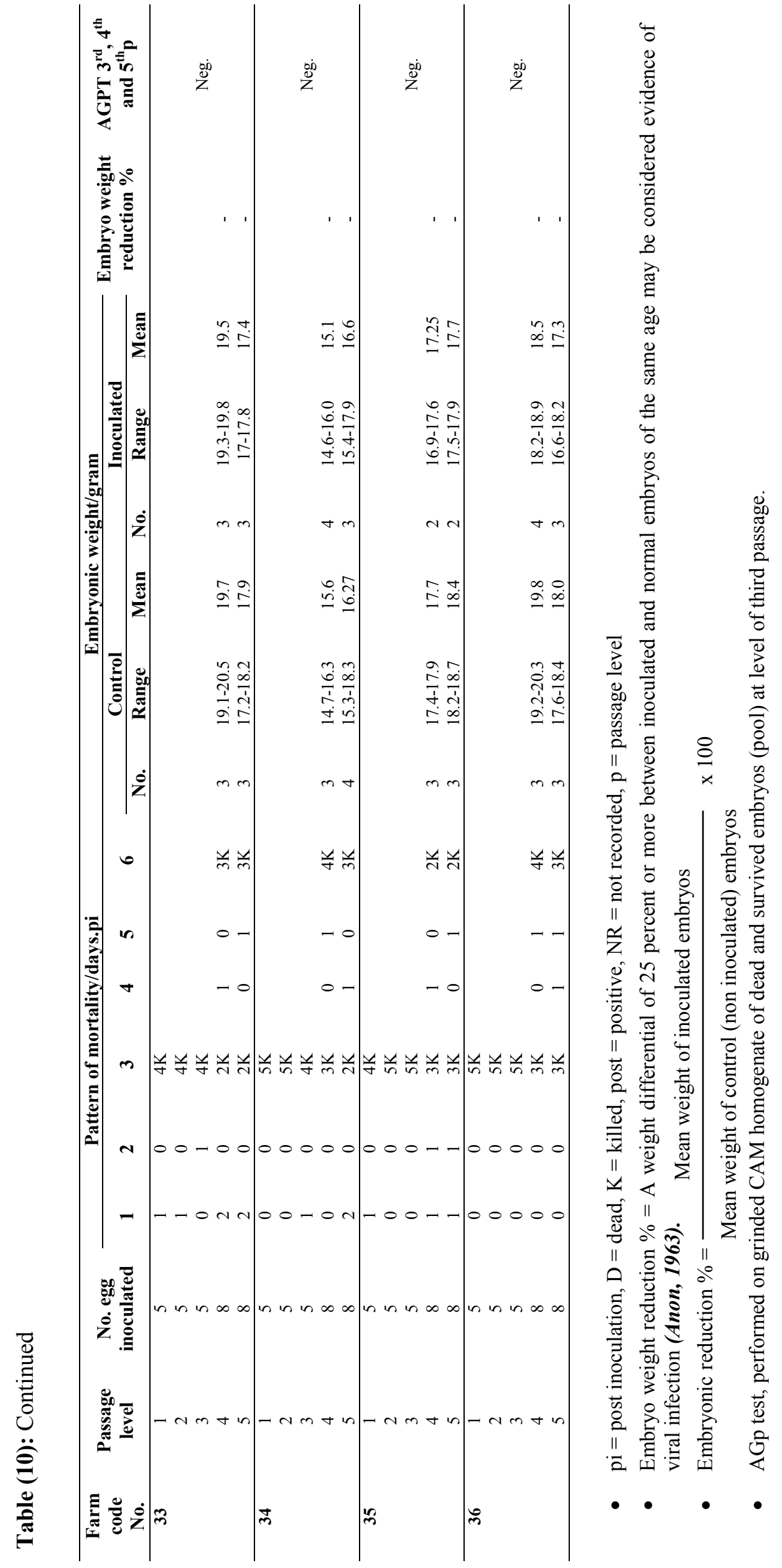


Cavanagh, D. and Naqi, S. A. (1997): Infectious bronchitis. In B.W. Calnek, H.J. Barnes, C.W. Bearol, L.R. Mc Daugald, and Y.M. Saif (eds). Disease of Poultry $10^{\text {th }}$ Ed. Lawa University Press: Ames, IA, 511-526.

Cavanagh, D. and Naqi, S. A. (2003): Infectious bronchitis in Disease of poultry. B.W Calnek, H.J. Barnes, C.W. Beard, L.R. Mc Dougald and Y.M. Saif (Eds). Disease of Poultry, $11^{\text {th }}$ edn (pp101-119). Ames, IA, Iowa State University Press.

Chubb, R. C. and Cumming, R. B. (1972): The use of the gel diffusion precipitin technique with avian infectious bronchitis Nephritis viruses. Aust. Vet. J., 47: 496-499.

Clarke, J. K.; McFerran, J. B. and Gay, F. W. (1972): Use of allantoic cells for detection of avian infectious bronchitis virus. Arch ges Virus forsch, 36, 62-70.

Cook, J. K. and Huggins, M. B. (1986): Newly isolated serotypes of infectious bronchitis virus: their role in disease. Avian Pathol., 15: 129-138.

Cook, J. K. A.; Brown, A. J.; Brocewell, C. D. (1987): Comparison of the hemagglutination inhibition test and the serm neutralization test in tracheal organ culture for typing infectious bronchtis virus strains. Avian Pathol., 16: 505511.

Cumming, R. B. (1970): Studies on Australian infectious bronchitis virus. IV. Apparent farm - to - farm airborne transmission of infectious bronchitis virus. Avian Dis., 14: 191-195.

Cunningham, C. H. and Jones, M. H. (1953): The effect of different routes of inoculation on the adaptation of infectious bronchitis virus to embryonating chicken eggs. Proc. Book, Am. Vet. Med. Assoc., 337-342.

Dutta, K. S. (1975): Morphological changes of chicken tracheas and tracheal organ culture infected with avian infectious bronchitis virus studied in scanning Electron microscop. Avian Dis., 19: 429-436.

Eissa, Y. M.; Zaher, A. and Nafai, E. (1963): Studies on respiratory diseases: Isolation of infectious bronchitis virus. J. Arab. Vet. Med. Assoc., 23: 381-389

El-Kady, M. F. (1989): Studies on the epidemiology and means of central of infectious bronchitis disease in chickens in Egypt. Ph. D. Thesis (Poultry Dis). Fac. Vet. Med., Cairo Univ., Giza, Egypt.

El-Sisi, M. A. and Eid, Amal, A. M. (2000): Infectious bronchitis virus and infectious bursal disease, concurrent infection among broilers in Egypt. Zagazig. Vet. J., 28: 150153

Gelb, J., Jr. (1989): Infectious bronchitis. In: purchase et al (Eds). A Laboratory Manual for the Isolation and Identification of Avian Pathogens. $3^{\text {rd }}$. ed. AAAP, 124-127. Gelb, J., Jr. and Jackwood, M. K. (1998): Infectious bronchitis. In: A laboratory manual for the Isolation and Identification of Avian Pathogens. ${ }^{\text {th }}$ ed. AAAP: 169-174.

Gelb, J., Jr.; Wolf, J.B. and Moran, C. A. (1991): Variant serotypes of infectious bronchitis virus isolated from commercial layer and broiler chickens. Avian Dis., 35:8287.

Gelb, J. Jr.; Keeler, C. L.; Nix, W. A.; Rosenberger, J. K. and Cloud, S. S. (1997): Antigenic and S1 genomic characterization of Delaware variant serotype of infectious bronchitis virus. Avian Dis., 41:661-669.

Gough, R. E.; Randall, C. J.; Dagless, M.; Alexander, D. J.; Cox, W. J. and Pearson, D. (1992): A new strain of infectious bronchitis virus infecting domestic fowl in Great Britain. Vet. Rec., 131: 408-411.
Gubillos, A.; Ulloa, J.; Gubillos, V. and Cook, J. K. (1991): Characterization of strains of infectious bronchitis virus isolated in Chile. Avian Pathol., 20: 85-99.

Hofstad, M. S. (1981): Cross-immunity in chickens using seven isolates of avian infectious bronchitis virus. Avian Dis., 25: 650-654.

Hofstad, M. S. (1984): Avian infectious bronchitis. In: Diseases of poultry, $8^{\text {th }}$ ed. Iowa State University Press: Ames, IA, 429-443.

Hopkins, S. R. (1974): Serological comparisons of strains of infectious bronchitis virus using plaque purified isolants. Avian Dis., 18: 231-239.

Ignjatovic, J. and Sapats, S. (2000): Avian infectious bronchitis virus. Rev. Sci. Off. Int. Epiz., 19: 493-508.

Jose, Di F.; Lavinia, I.; Rossini, S. J.; Orbell, G. P.; Micheal B.; Huggins, A. M.; Byron, G.; Silva, M. and Cook J. K. (2000): Characterization of infectious bronchitis viruses isolated from outbreaks of disease in commercial flocks in Brazil. Avian Dis., 44: 582-589.

Lebdah, M. A.; Eid, Amal, A. M. and El-Shafey, A. M. (2004): Infectious bronchitis virus infection among meattype chickens in sharkia province (Egypt). Proc. IV. Int. Symp. On avian Corona-and pneumovirus infections. Rauischholzhausen, Germany, 20-23 June, 2004. pp. 75-86. Lucio, B. and Fabricant, J. (1990): Tissue tropism of three cloacal isolates and Massachusetts strain of infectious bronchitis virus. Avian Dis., 26, 508-519.

McMartin, D. A. (1993): Infectious bronchitis. In: Virus infections of birds (McFerran, J.B. and McNulty, M.S, eds). Elsevier Science Publisher, Amsterdam, 249-274.

Office international des Epizootics (OIE) (1996): Avian infectious bronchitis, chapter 3.6.6. In Manual of standards for diagnostic test and vaccines, $3^{\text {rd }}$ ed. OIE, Paris 539-548. Parsons, D.; Ellis, M. M.; Cavanagh, D. and Cook, J. K. (1992): Characterization of an infectious bronchitis virus isolated from IB-vaccinated broiler breeder flocks. Vet. Rec., 131: 408-411.

Schalk, A. F. and Hawn, M. C. (1931): An apparently new respiratory disease of chicks. J. Am. Vet. Med. Assoc., 78: 413- 422.

Sultan, H. A.; Tantawi, Lila, A.; Youseif, Aml, I. and Ahmed, A.A.S. (2004): Urolethiasis in white commercial egg laying chickens associated with an ifnectious bronchitis virus. Proc. $6^{\text {th }}$. Sci. Conf. Egypt. Vet. Poult. Assoc., pp: 155-169.

Villegas, P. and Purchase, G.H. (1990): Preparation of chicken embryo kidney cell cultures (CEKC). In: Laboratory manual for the isolation and identification of avian pathogens. AAAP. Ames, Iowa, USA. pp: 3-4.

Wang, C.H. and Tsai, C.T. (1996): Genetic grouping for the isolates of avian infectious bronchtis viruses in Taiwan. Arch. Virol., 141: 1677-1688.

Wang, Y.D.; Wang, Y.L.; Zhang, Z.C.; Fan, G.C.; Hiang, Y.H.; Liu, X.e.; Ding, J. and Wang, S.S. (1998): Isolation and identification of glaudular stomach type IBV (QX-IBV) in chickens. Chin. J. Animal Quarr., 15: 1-3.

Woernle, H. (1966): The use of the agar-gel diffusion technique in the identification of certain avian disease. The Veterinarian, 4: 17-28.

Yu, L.; Wang, Z.; Jiang, Y.; Low, S. and Kwang, J. (2001): Molecular epidemiology of infectious bronchitis virus isolates from China and southeast Asia. Avian Dis., 45: 201-209. 


$$
\text { 1. القاء الضوء على انتشار مرض الإلتهاب الشعبى المعدى فى بعض قطعان الاجاج مشاكل الإلتهاب الشعبى المعدى فى بعض قطعان الدجاج }
$$

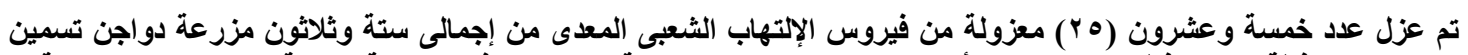

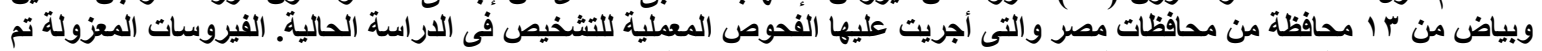

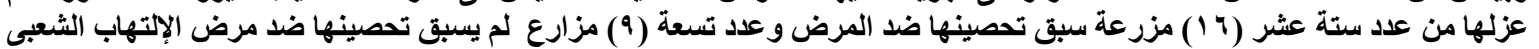

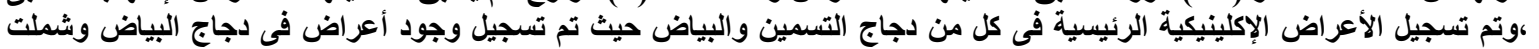

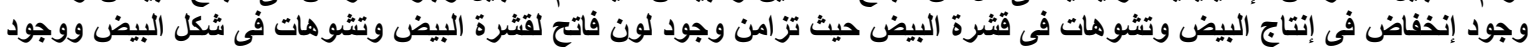

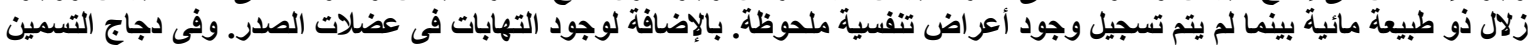

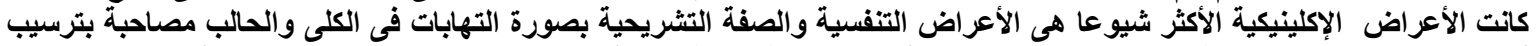

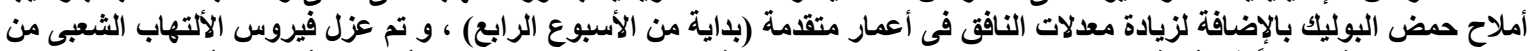

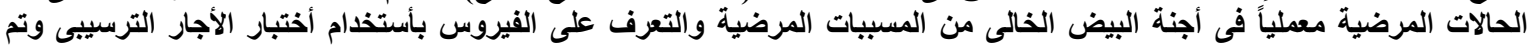

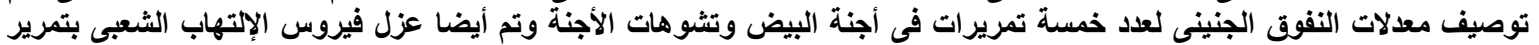

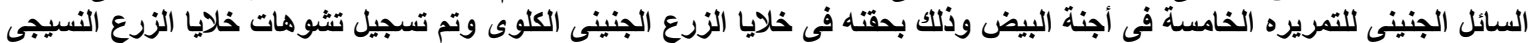
لعدد أربعة تمريرات متتالية. 